Who really bears the cost of education?

\title{
How the burden of education
} expenditure shifts from the public to the private sector

\section{EDUCATION} INDICATORS IN FOCUS NOVEMBER 2017
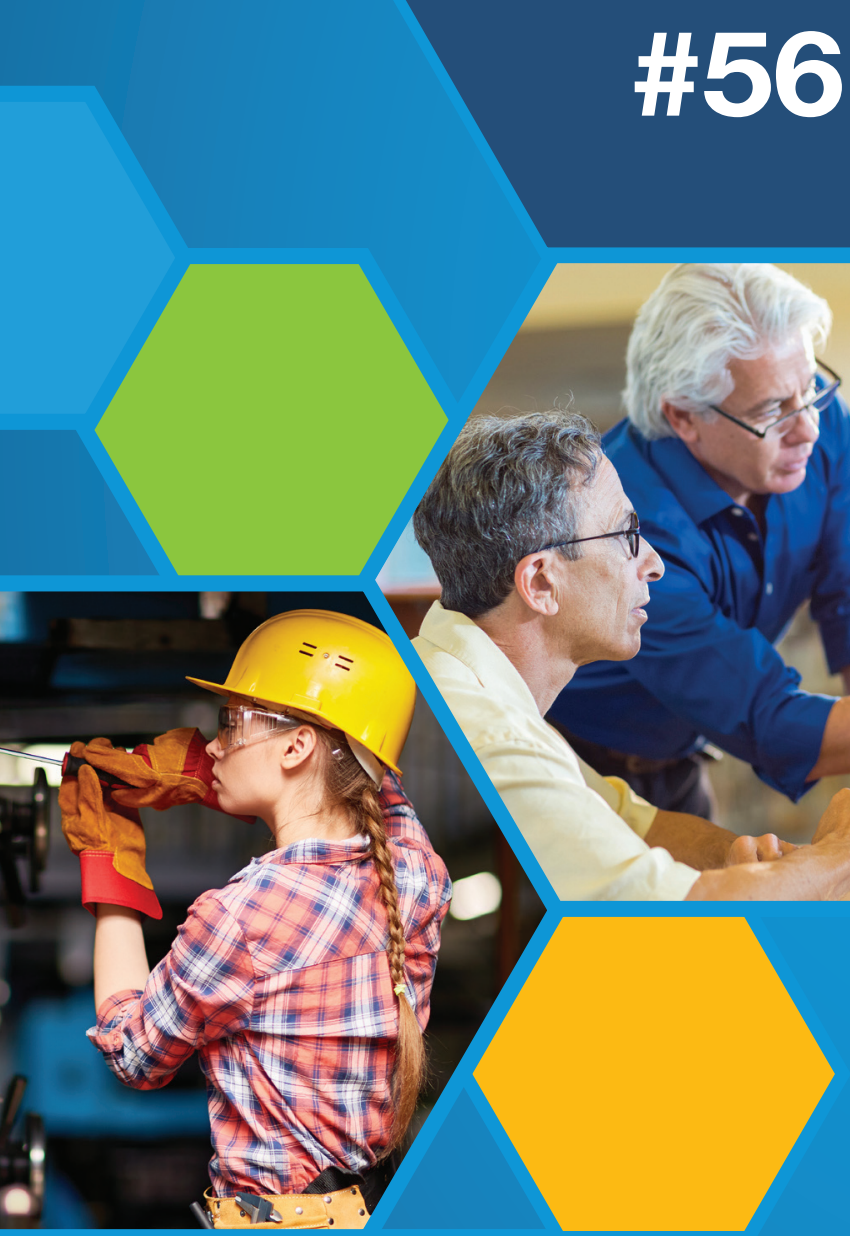
- Public to private transfers play an important role in funding education through indirect channels, especially at the tertiary level.

- Private expenditures can be sourced in different ways: loans are an important type of government transfer, particularly at tertiary level, although most countries favour grants.

- Countries where private funding makes up a larger share of education expenditure often have the lowest share of public transfers: this may inhibit access to learning.

- Public to private transfers in the form of student loans are a way for governments to reduce out-of-pocket expenses for students while recuperating the funds later through loan repayments.

\section{Concepts and definitions}

Public expenditure on education includes direct public funding for educational institutions. Private expenditure refers to expenditure funded by private sources (households and other private entities) such as tuition fees and other student or household payments to educational institutions and outside institutions.

Public to private transfers of funds can be considered as public or private expenditure, depending on the type of analysis. Public to private transfers are considered public expenditure when presenting the initial source of funds before the transfers have been made to private entities, and as private expenditure when presenting the final source of funds after the transfers have been made.

Public to private transfers include: 1) grants/scholarships (non-repayable subsidies); 2) public student loans (which must be repaid); and 3) government transfers and some other payments (mainly subsidies) to other private entities (commercial companies and non-profit organisations). These transfers and payments can take diverse forms, such as transfers to business or labour associations that provide adult education, subsidies to companies or labour organisations (or associations of such entities) that operate apprenticeship programmes and interest-rate subsidies or default guarantee payments to private financial institutions that provide student loans.

Total expenditure on education is the sum of public and private expenditure as well as public transfers. It covers expenditure on educational institutions and outside institutions.

\section{Public to private transfers of funds help support the private cost of education}

The financial resources devoted to education are a combination of resources from governments, private institutions and individual students and their families. A large share of government spending 
goes directly to institutions but governments also transfer funds to educational institutions through various other allocation mechanisms (through tuition subsidies or direct public funding of institutions based on student enrolments or credit hours) or by subsidising students, households and other private entities (through scholarships, grants or loans).

Governments use these transfers to provide institutions with incentives to organise their educational programmes and teaching to better meet student requirements, and to increase access to education and reduce social inequalities. Channelling funding for institutions through students helps increase competition among institutions and results in greater efficiency in the funding of education. Since aid for student living costs can also serve as a substitute for labour income, public transfers may enhance educational attainment by enabling students to study full-time.

In OECD countries, public to private transfers play an important role in indirectly funding education (Figure 1), although they only represent around 3\% of the total expenditure at primary, secondary and post-secondary non-tertiary levels. At this level, Australia, Mexico and the Netherlands have the highest share of such public transfers (above $5 \%$ of the total expenditure), while Japan, the United Kingdom and the United States have the lowest share (below 0.5\%).

FIGURE 1 / Distribution of transfers and public and private expenditure on education (2014)

By level of education

Public expenditure Public to private transfers $\quad$ Private expenditure
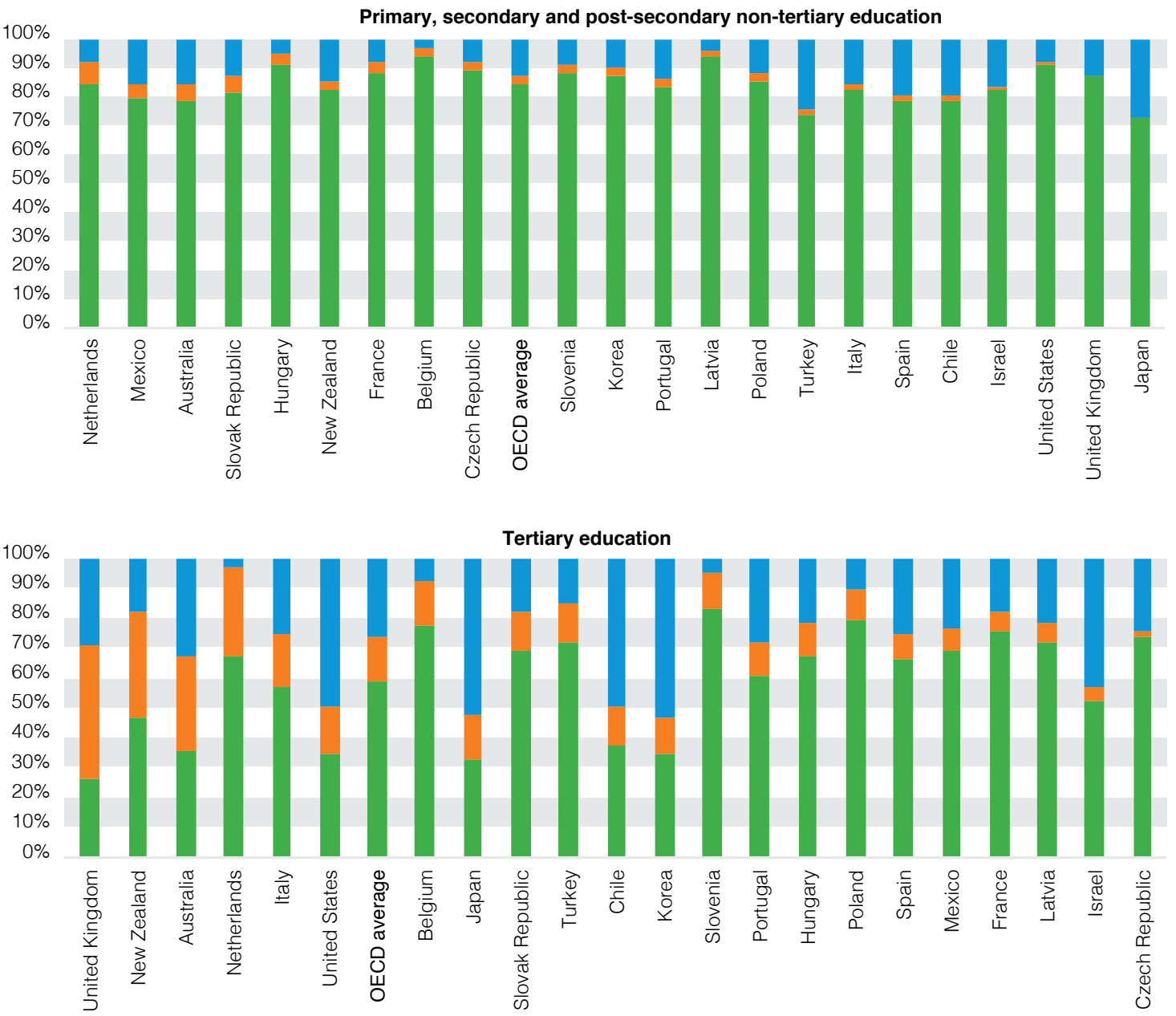
ranked in descending order of the proportion of public to private transfers. 
At tertiary levels, public transfers represent a larger share of the total expenditure on average. However, there are large differences across countries, ranging from 30\% or more in Australia, the Netherlands, New Zealand and the United Kingdom, to less than 10\% in France, the Czech Republic, Israel, Latvia, Mexico and Spain.

\section{Loans are an important type of public transfers at tertiary level but most countries favour grants}

The types of public support offered encourage the expansion of educational attainment, particularly at tertiary level where private spending is the greatest. The way public funds are transferred to private entities varies widely across OECD countries (Figure 2). In 2014, the most common type of transfer was scholarships and grants, although their contribution to total expenditure is limited ( $9 \%$ on average across countries). In one-third of countries with available data, public to private transfers are made up almost exclusively of grants or scholarships. The remaining countries make greater use of loans in addition to grants. In particular, loans make up more than two-thirds of total public to private transfers in Australia, New Zealand and the United Kingdom. These are also the countries with the highest share of private expenditure at the tertiary level, and these countries mitigate the financial burden on students through measures such as income-contingent repayments complemented by a means-tested grants scheme. Public transfers have the benefit of promoting access and equity and lead to better outcomes for students (OECD, 2012).

FIGURE 2 / Public to private transfers as a percentage of total expenditure on tertiary education (2014)

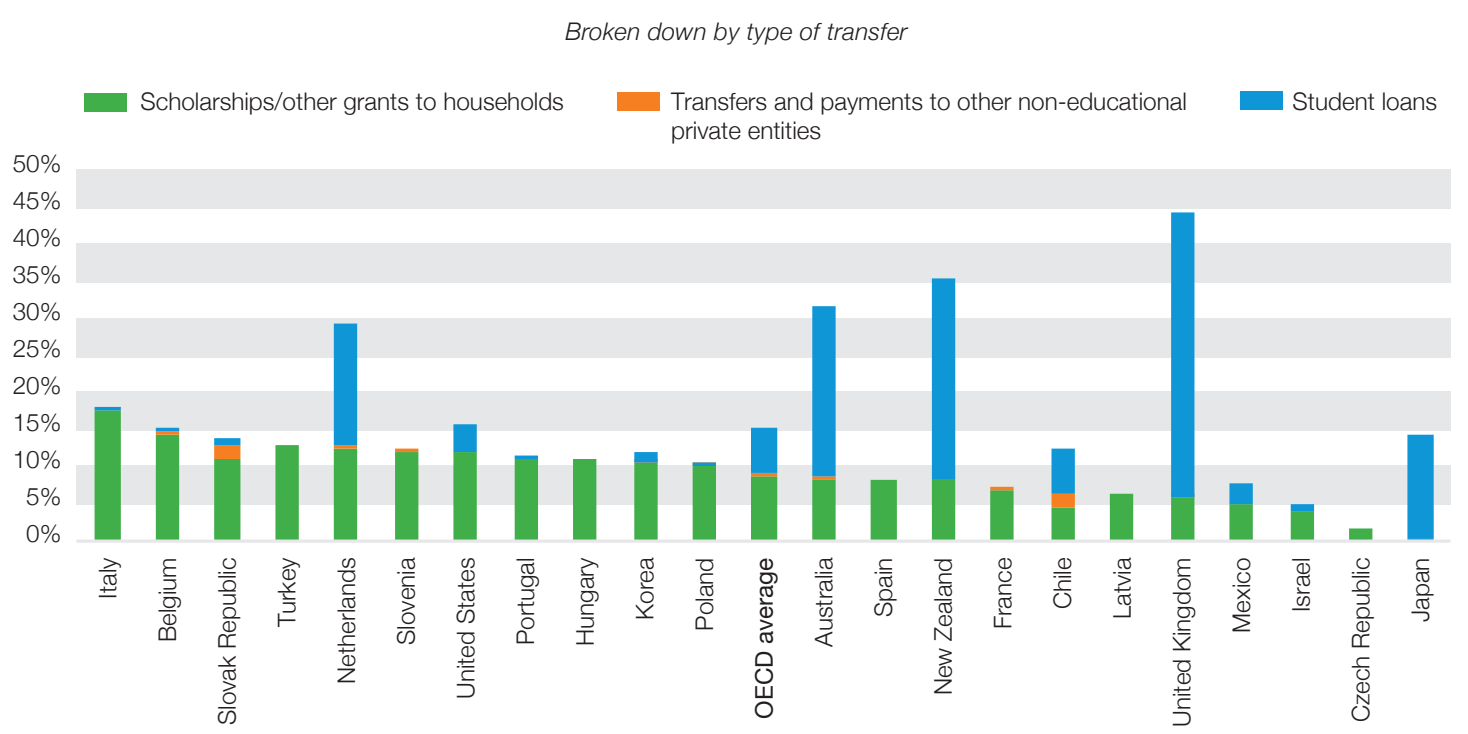

Note: $\quad$ The figures for the United States are for net student loans rather than gross, therefore underestimating public transfers. Countries are ranked in descending order of the proportion of scholarships and transfers and payments to other non-educational private entities as a percentage of total expenditure on tertiary education.

Source: OECD (2017), Education at a Glance Database, http://stats.oecd.org/.

\section{Are public transfers sufficient to cover the private costs of education?}

Governments face the challenge of striking the right balance between providing sufficient support to the private funders and making efficient use of limited public funds. Despite the considerable impact of public transfers on reducing the financial burden of access to education for students, households and other private entities, government support seems to only cover a relatively small share of the private costs of education in some countries while in others private spending is largely covered by public transfers. This creates challenges for access and learning as higher private spending could deter students from participating in education. 
Across all levels of education, the proportion of public to private transfers as a share of total private spending tends to decrease as the share of private spending on education increases. Countries in Quadrant IV of Figure 3 represent those with a high share of private expenditure and a relatively low share of public transfers. In contrast, countries in Quadrant I show a lower share of private expenditure but a larger share of public transfers.

There is no single allocation model across OECD countries. Countries in Quadrants III and I show lower shares of private spending but different kinds of public transfers. For instance, in Latvia and Turkey private funding accounts for an almost identical share of expenditure on tertiary education, but public to private transfers in Turkey are almost double (in relative terms) what they are in Latvia. Similar differences are observed among countries with a larger share of private expenditure devoted to education (those in Quadrants IV and II). For example, even though the share of private expenditure is almost identical in Chile and Australia, Australia publicly supports a large share of the private cost in the form of student loans, relieving private funders at least temporarily, until they have the means to start repaying.

FIGURE 3 / Share of private expenditure on education as a percentage of total expenditure and public transfers as a percentage of private expenditure (2014)

By level of education
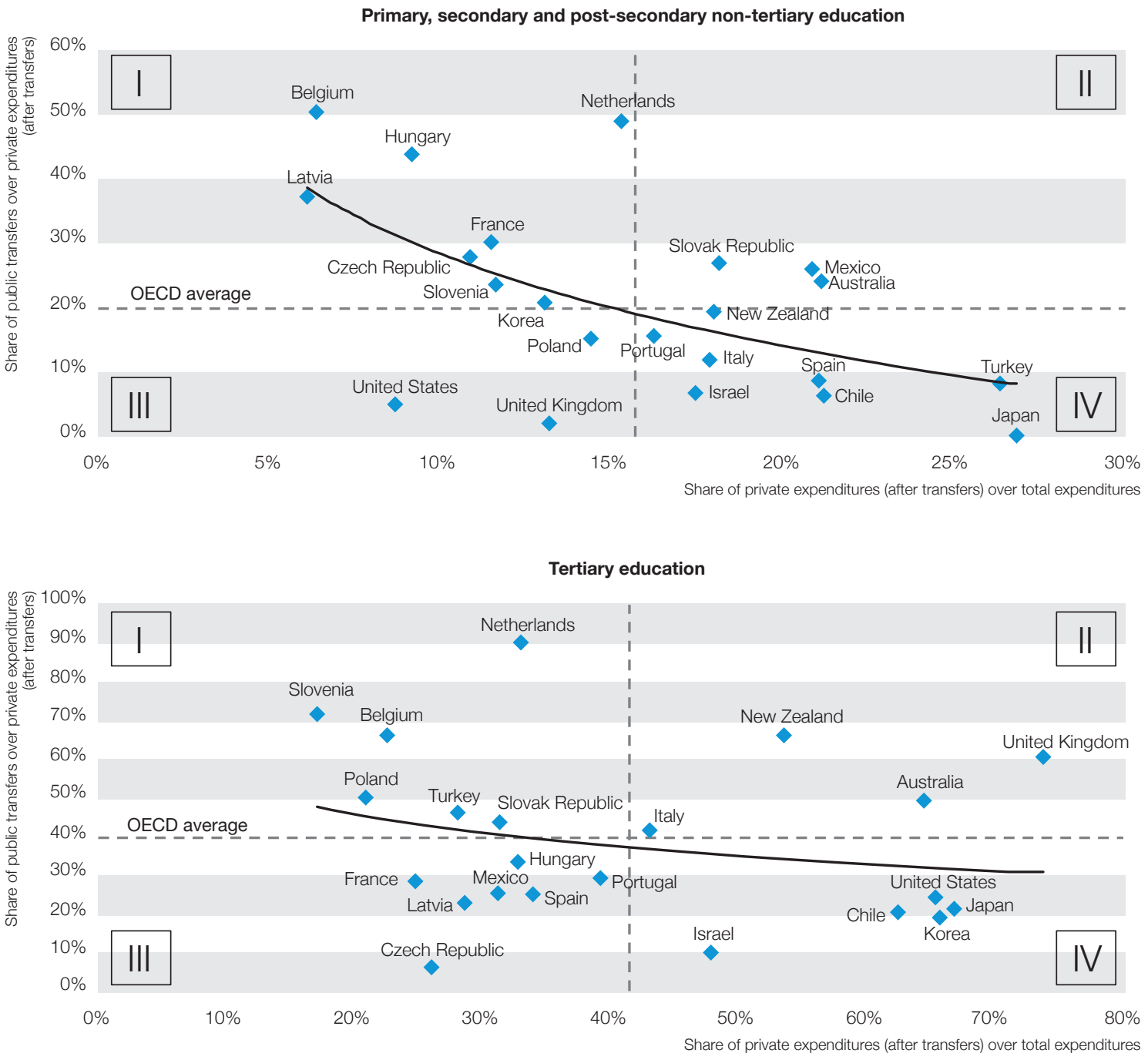

Note: $\quad$ The figures for the United States are for net student loans rather than gross, therefore underestimating public transfers.

Source: OECD (2017), Education at a Glance Database, http://stats.oecd.org/. 
Countries also vary in the way they allocate funds and expect private funders to contribute across different education levels. Countries such as Mexico and Turkey expect a higher contribution from private funds for school education than on average across OECD countries, but a lower than average contribution at tertiary level, demonstrating strong prioritisation of encouraging higher education attainment. The opposite is observed in Korea, the United Kingdom and the United States, where the acquisition of basic skills is largely publicly provided, but private funding is expected to contribute more to the funding of higher education.

Governments are struggling to adapt tuition and financial aid policies in response to the rising costs of education, and the rising returns on schooling in form of higher earnings as well as the increasing labour market risks such as unemployment. In a period of tight budgets the analysis of how public transfers could help to support private funding could be an important element of the design of new and better policies to increase access to education at all levels.

\section{The bottom line}

Despite the obvious benefits derived from education, governments face difficult trade-offs when balancing the share of public and private contributions to education.

Understanding how private expenditure is sourced, through public transfers or through private funds, can make a difference in enabling access to education and provide insights into how the cost of education shifts between public and private sources of funding over time.

\section{FOR MORE INFORMATION:}

OECD (2017), Education at a Glance 2017: OECD Indicators, OECD Publishing, Paris, http://dx.doi.org/10.1787/ eag-2017-en.

OECD (2012), "How are countries around the world supporting students in higher education?", Education Indicators in Focus, No. 2, OECD Publishing, Paris, http://dx.doi.org/10.1787/5k9fd0kd59f4-en. do not necessarily reflect the official views of OECD member countries.

This document, as well as any data and any map included herein, are without prejudice to the status of or sovereignty over any territory, to the delimitation of international frontiers and boundaries and to the name of any territory, city or area.

The statistical data for Israel are supplied by and are under the responsibility of the relevant Israeli authorities. The use of such data by the OECD is without prejudice to the status of the Golan Heights, East Jerusalem and Israeli settlements in the West Bank under the terms of international law. 